\title{
The Case for Anatomy
}

Amalia Namath, $\mathrm{MSc}^{1}$ (i)

${ }^{1}$ Georgetown University School of Medicine

Keywords: medical education, anatomy, cadaver

https://doi.org/10.52504/001c.11889

\section{Georgetown Medical Review}

Vol. 4, Issue 1, 2020

\begin{abstract}
As anatomy programs around the country turn away from use of cadavers, it is important to underline the unique experience that gross anatomy provides to medical students. This article provides commentary on anatomy as a fourth year medical student, looking back on the gross anatomy course after the chance to return as a teaching assistant.
\end{abstract}

The first thing I remember is the smell. Stepping back into the anatomy lab, the smell is unlike anything else- it's one that many try to forget but remains hauntingly familiar the moment it hits my nostrils. A few years had passed since I had last been in the anatomy lab, but the smell immediately brought me back. With the smell came a flood of memories-meeting my 4 lab mates and bonding as we spent hours hunched over our cadaver. Often, we would share our favorite recipes as the lab would wind down, in part because of the aptly named "formaldehyde hunger" and to find common ground. We had some great times, sharing laughs over the mispronunciation of pterion fossa, having frequent discussions on what specialty we would all choose in 4 years' time, and chattering about our weekends. We also experienced hard times, like when we felt completely lost and unable to find the obturator nerve, convinced one of us had accidently severed it in the search while every other team seemed to have seamlessly discovered its location. We agonized for hours over that nerve and then realized it might just be easier to find it on the other side, and then laughed about it for the rest of lab.

For my group, and the rest of the class, it was the first year of medical school and anatomy was a rite of passage. To us, anatomy embodied what it truly meant to be a medical student. Older physicians had often regaled us with stories of when they were in anatomy lab, toiling away at dissection, and with that knowledge, we knew that this course was a cherished step forward into the role of a physician. It was also the first time we were exposed to the concept of death as a medical student, seeing what happened when disease got the upper hand, taking the life of our first patients.

The anatomy course passed quickly, starting with musculoskeletal and ending with neuroscience. And, before we knew it, the first year was almost over and it was time to say goodbye to the cadaver that had taught us so much. I remember that last day - we put everything together, zipped the case up, and then bowed our heads in a moment of silent gratitude for our very first patient. 
Now, as a fourth-year medical student, the majority of my year will be spent focused on the next step in my career: residency. This includes preparing residency applications, honing my skills, fulfilling elective requirements, and anxiously awaiting Match Day. You would think not much of that would harken back to the anatomy lab, but I had chosen to do a teaching elective where I would help in the gross anatomy classroom and do an individualized dissection on my own.

As I stepped back into the lab on my first day, with the familiar smell around me, I could not believe how much had changed. At this point, I had been a part of surgeries, assisting in the $\mathrm{OR}$, and helped manage patients on the wards and in clinics. I had seen life born and life lost, and I had discovered a specialty that I loved along the way. However, as I unzipped the bag that held the cadaver, I realized that there was still so much more I did not know. The anatomy of the human body is never quite the same, and as I spent hours dissecting the pelvic region, I realized that this will always hold true. As much as 3D imaging or projected bodies can teach anatomical models, there is no way to fully predict what anomalies the human body will hold. It made me recall my first cadaver-my first patient-who happened to have had a quadruple bypass, 2 mechanical valves, a cerebellar tumor, and no uterus. I remember having a patient when I was on my Neurology rotation who was found to have 2 left femoral veins and had suffered a stroke. All along the way, beginning in the gross anatomy lab, we learn as medical students that each human body is unique, requiring individualized care. Each patient has their own anatomical mapping, which is why imaging, lab work, and most importantly, the physical exam are integral to the care of the patient; their anatomy helps inform their treatment.

Knowing what I know now, and talking to my fellow fourth years about our journeys, we have all agreed that we share an appreciation for those very first patients and the course that introduced us to them. We reminisced; "Remember when we found out she had a pacemaker?" "I can't believe there were still gallstones there." "That dissection of the thyroid was the bane of my existence." "I have to say I will never forget where that darn obturator nerve is." Without gross anatomy and without true cadavers, one would never learn just how amazing the human body is, able to create extra vessels or adapt to a missing organ. The same way that we are taught to treat the patient as a whole-cura personalis, as it is known at Georgetown-is the way that we learn about anatomy, as a whole. I still remember my gross anatomy professor repeating that the way to figure out the anatomy and to determine what a structure is, is by relationships - the relationship of a nerve to an artery or of a vein to a lymph node. We could prove we had found the correct structure by showing where it had originated and, at the same time, we could figure out the anomalies that made our cadaver unique. 
So, as medical school programs around the country are decreasing anatomy hours and switching from human cadavers to projections, I wanted to make a case for gross anatomy. It was the place where I first learned what it meant to be a medical student and the first place I truly appreciated the human body in both its anatomical ubiquity and individuality. I may eventually forget the smell, but I know I will never forget all that I learned in the anatomy lab. From that first day, I knew that my first patient would help me learn how to treat patients to come, up to my very last. For that and more, I have anatomy to thank. 